steadily improved since then, with commensurate increases of cost, the British system is now much less of an international boast than it used to be. The quality of medicine is good, even though it can sometimes cause wry smiles when compared with practice elsewhere. The quality of the service provided is variable, to say the best of it. But hanging over everything is the fear that it may only be a matter of months before there is a rapid deterioration of the efficacy of the system. Plainly the health services have exhausted their goodwill with the nurses. But would the framework which Mr Crossman now proposes be able to meet the strain of paying nurses and other medical ancillaries at rates which are competitive? With this anxiety, is it sensible of him to complain about the continued success of the private medical insurance schemes which are flourishing alongside the health service? Might it not be more prudent to devise some method of mixed financing for the new health service? That is at least a question which deserves serious consideration, quite independently of party politics and separate from the commitment to a totally free health service on which $\mathrm{Mr}$ Aneurin Bevan nailed the present government's colours to the mast just twenty years ago.

\section{Yeurs Ago}

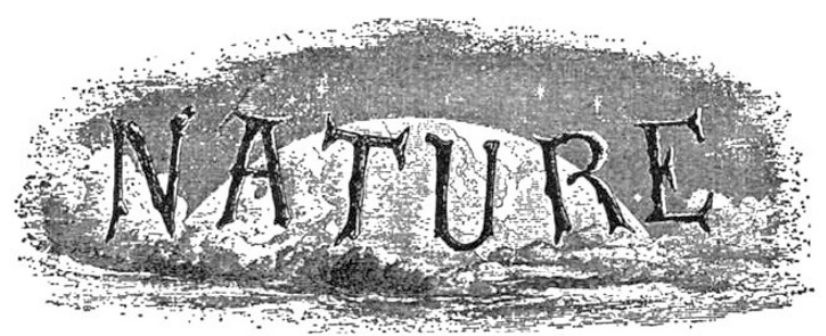

In fact, the Miocene Mammalian Fauna of Europe and the Himalayan regions contains associated together the types which are now separately located in the South African and Indian sub-provinces of Arctogæa. Now there is every reason to believe, on other grounds, that both Hindostan, south of the Ganges, and Africa, south of the Sahara, were separated by a wide sea from Europe and North Asta, during the middle and upper Eocene epochs. Hence it becomes highly probable that the well-known similarities and no less remarkable differences between the present Faunz of India and South Africa have arisen in some such fashion as the following. Sometime during the Miocene epoch, possibly when the Himalayan chain was elevated, the bottom of the nummulitic sea was upheaved and converted into dry land, in the direction of a line extending from Abysinia to the mouth of the Ganges. By this means the Dekhan on the one hand, and South Africa on the other, became connected with the Miocene dry land and with one another. The Miocene Mammals spread gradually over this intermediate dry land, and if the condition of its eastern and western ends offered as wide contrasts as the valleys of the Ganges and Arabia do now, many forms which made their way into Africa must have been different from those which reached the Dekhan, while others might pass into both these sub-provinces.

That there was a continuity of dry land between Europe and North America during the Miocene epoch, appears to me to be a necessary consequence.

From T. H. Huxley's valedictory address to the Geological Society, of which he had been president for the past two years. Nature, 1, 443, February 24, 1870.

\section{OLD WORLD}

DRUGS

\section{More L-Dopa in Sight}

InITIAL enthusiasm for the drug L-dopa in the treatment of Parkinson's disease seems to have been justified by the results of trials carried out so far. But the problem of supply is still formidable, although the Committee on the Safety of Drugs, in the thick of dealings with chemical and pharmaceutical companies, is doing its best to approve the use of new and reliable preparations.

Impressive evidence of the beneficial effects of the drug was seen at the first open meeting of the Parkinson's Disease Society in London on February 11. A film of two women sufferers whose unsteady gait and handwriting returned almost to normal after treatment was shown by Dr G. Stern, consultant neurologist at University College Hospital, London. This is one of five British centres where clinical trials of the drug are in progress under the auspices of the Medical Research Council. L-Dopa is, of course, the drug which was seen as a potential treatment for Parkinsonism when drugs which cause a decrease in amounts of monoamines, particularly dopamine, in the brain were found to cause the disease (Nature, 223, 889; 1969).

Stern says that these patients are not his most successful cases; in some, for example, manual dexterity has apparently returned to normal from a very poor state. On the whole he finds that two-thirds of Parkinson patients treated with L-dopa during the trials have responded to varying degrees, while for the other third treatment has had no effect. These findings are similar to those reported in the British Medical Journal by Dr C. Mawdsley of the University of Edinburgh $(1,333 ; 1970)$. Of twenty patients treated for an average of six months he reported marked improvement in nine; this involved renewed ability to rise from a chair and walk comfortably without the need for aid. Fourteen patients experienced moderate improvement, in five it was only slight and a further five experienced no improvement.

Many Parkinson patients treated with L-dopa develop side effects - nausea and loss of appetite seem to be the commonest. Induced voluntary movements of the face and feet are also a frequent effect, but not usually distressing, disappearing as the dose is reduced. Psychiatric effects such as depression may pass off after a few days of treatment. Two of Mawdsley's patients developed hallucinations and paranoid delusions; one refused to take any more of the drug, but the other lost the symptoms when the dose was reduced.

There are clearly various possible side effects of L-dopa, and although many of them seem to be mild enough to accept for the sake of the benefits, neurologists involved in the trials must have great respect for the unknown element. As Stern told his audience on February 11, it is impossible to see yet how long the favourable effects of treatment will last. $\mathrm{He}$ was careful to stress that although L-dopa is the most effective form of treatment so far found for some patients, it is not a cure for Parkinsonism. When the drug becomes available for regular treatment patients 